\title{
IMPASSES E CONTROVÉRSIAS NA CONSTRUÇÃO DA MEMÓRIA HISTÓRICA DA IGREJA CATÓLICA NO BRASIL
}

\author{
OBSTÁCULOS Y CONTROVERSIAS EN LA CONSTRUCCIÓN DE LA MEMORIA \\ HISTÓRICA DE LA IGLESIA CATÓLICA EN BRASIL \\ IMPASSES AND CONTROVERSIES IN THE CONSTRUCTION OF THE HISTORICAL \\ MEMORY OF THE CATHOLIC CHURCH IN BRAZIL
IMPASSES ET CONTROVERSES DANS LA CONSTRUCTION DE LA MÉMOIRE HISTORIQUE DE L’ÉGLISE CATHOLIQUE AU BRÉSIL

\author{
DOI: $\underline{10.5533 / 1984-2503-20113203}$
}

Jessie Jane Vieira

\section{RESUMO}

Nesse trabalho busco apresentar, de forma resumida, a trajetória do mais importante representante do catolicismo conservador ${ }^{1}$ brasileiro, em torno do qual existem varias controvérsias que começam a se manifestar nas operações de memórias recentemente acionadas. Trata-se do ex-cardeal do Rio de Janeiro que, para muitos, foi o responsável pela virada conservadora da Igreja no Brasil. Tento entender os motivos pelos quais este "príncipe da Igreja", extremamente cioso da sua autoridade e com grande prestigio social, busca construir uma nova narrativa sobre si mesmo e sobre sua atuação enquanto arcebispo e cardeal ao longo do período ditatorial.

Palavras-chave: memória, história, Igreja Católica, política, poder.

\section{RESUMEN}

En este trabajo intento presentar, de manera resumida, la trayectoria del más importante representante del catolicismo conservador brasileño en torno al cual existen varias controversias que empiezan a manifestarse en las operaciones de memorias recientemente accionadas. Se trata del ex Cardenal de Río de Janeiro que, para muchos, fue lo

\footnotetext{
${ }^{1}$ Aqui não utilizo o termo como sinônimo de integrista, mas para designar aqueles que combateram a Teologia da Libertação.
} 
responsable por la vuelta conservadora de la Iglesia en Brasil. Intento comprender los motivos por los cuales este "príncipe de la Iglesia", extremamente atento a su autoridad y con gran prestigio social, busca construir una nueva narrativa sobre si mismo y sobre su actuación en cuanto arzobispo y cardenal a lo largo del periodo dictatorial.

Palabras clave: Memoria, Historia, Iglesia Católica, Política, Poder.

\section{ABSTRACT}

This study presents, in summary form, the trajectory of the former Cardinal of Rio de Janeiro, one of the most important representatives of conservative Brazilian Catholicism, around whom there have been several controversies about memories that have recently been reawakened. Many people believe that the Cardinal was responsible for conservatizing the Church in Brazil. We discuss the reasons why this "prince of the Church," extremely jealous of his authority and with high social prestige, has sought to build a new narrative about himself and about his role as archbishop and cardinal during the dictatorship era.

Keywords: memory, history, Catholic Church, politics, power,

\section{RÉSUMÉ}

Ce travail cherche à présenter brièvement la trajectoire du plus important représentant du catholicisme conservateur brésilien, autour duquel existent de nombreuses controverses qui ont commencé à se manifester au sein de constructions de la mémoire récemment mises en œuvre. Il s'agit de l'ex-Cardinal de Rio de Janeiro, qui est considéré par beaucoup comme le principal artisan du virage conservateur amorcé par l'Église au Brésil. Nous avons analysé les raisons pour lesquelles ce «prince de l'Église », extrêmement jaloux de son autorité et au prestige social important, cherche à construire de nouveaux récits sur lui-même et sur ses agissements en tant qu'archevêque et cardinal durant la période dictatoriale.

Mots-clés : Mémoire, histoire, Église catholique, politique, pouvoir. 


\section{Introdução}

Apesar dos vários acervos documentais já disponibilizados nas paróquias ou nos arquivos públicos e privados, as pesquisas sobre o protagonismo dos católicos e da hierarquia católica durante a ditadura militar implantada no Brasil em 1964 ainda é um tema à espera dos historiadores. Os projetos de pesquisas que nos chegam, a nós professores das universidades públicas interessados nessa temática, estão basicamente concentradas nas trajetórias dos bispos tidos como progressistas ou em algum movimento que tenha se projetado ao longo do período. Em geral, tais projetos terminam por produzir narrativas laudatórias que partem de uma perspectiva muito marcada por certo senso comum a respeito do que foi, ou é, a Teologia da Libertação.

Penso que, na essência, tais abordagens buscam monumentalizar a memória de alguns bispos ou de determinados grupos católicos para interrogar o presente, realizando uma operação complexa onde podemos falar de processos subjetivos em busca da construção de significados para o passado, mas onde os sujeitos se movem e se orientam em direção ao futuro.

Nesta perspectiva, tais projetos de pesquisa partem da premissa de que as memórias dos ícones do catolicismo têm poder para revelar uma suposta verdade na qual, a despeito do que chamam de "descaminho" imposto pelo papa João Paulo II, a Igreja da Teologia da Libertação teve papel profético na luta contra a ditadura. Para muitos destes jovens que nos chegam em busca de orientação, não se trata de construir uma memória social da Igreja, como exercício intelectual, mas de projetar uma memória pessoal que por vezes tenta dissociar tais bispos do contexto institucional e histórico no qual eles se moviam. Como exercício esta talvez possa ser uma experiência interessante, mas desde que trabalhada sem esquecer as vivências prévias à ditadura e sem deixar de apontar os limites existentes entre religião e política.

Outra questão importante é a visão, também ancorada em senso comum, que divide os bispos em campos opostos como se existissem protagonismos pessoais que se sobrepusessem aos interesses institucionais. E aqui surge outro problema que é o de tomar tais bispos como pessoas e não como representantes da institucionalidade católica. Ainda que tenham tido pertencimentos a correntes diferentes e que disputassem internamente 
diferentes projetos pastorais, isso não quer dizer que tivessem antagonismos essenciais em relação às suas lealdades institucionais.

Creio que são estas disputas que se manifestam hoje nas operações de memória que estão em marcha no Brasil. E, vale ressaltar, que hoje estes bispos estão jubilados, mas continuam sendo ativos em muitos espaços e referências para os jovens militantes católicos que se constituem em operadores destas múltiplas memórias no interior da Igreja brasileira.

No caso do Brasil não se trata de uma memória defensiva, mas, como já apontado, de ressaltar, ou monumentalizar, determinadas memórias relacionadas aos bispos representantes da chamada Teologia da Libertação. Os empreendedores de memória têm sido incansáveis na publicização das memórias destes bispos que se tornaram referência ainda que de um projeto derrotado no interior da Igreja e da sociedade. Contudo, a despeito das narrativas sobre esta teologia, a memória institucional vencedora é a de que a lgreja, como um todo, foi contra a ditadura, defensora dos direitos humanos e o único espaço de atuação das oposições ao regime.

Mas os depoimentos de alguns bispos, comprometidos com a Teologia da Libertação, indicam que nas reuniões anuais da Conferencia Nacional dos Bispos do Brasil (CNBB), existiam grandes disputas para que a instituição se manifestasse mais explicitamente contra a ditadura, já que a maioria dos membros da hierarquia apoiava uma atitude no mínimo complacente para com o regime. Para estes bispos aquela Igreja era conservadora e os documentos produzidos pela CNBB naquele período foram frutos de intensas disputas políticas no campo católico. Todavia, tais disputas não são valorizadas nas narrativas monumentalizadas $\mathrm{e}$ as memórias dos bispos considerados conservadores estão subsumidas a uma memória oficial, institucional, na qual a lgreja, como um todo, foi o protagonista heroico na resistência à ditadura.

Penso que seria importante recuperar criticamente as memórias de alguns destes bispos e dos assessores da CNBB, especialistas que ao longo daqueles anos desempenharam importantes tarefas nas conferências e nas analises produzidas e publicadas pela Instituição. Neste trabalho busco apresentar, de forma resumida, a trajetória do mais importante representante do catolicismo conservador ${ }^{2}$ brasileiro e em torno do qual

\footnotetext{
${ }^{2}$ Aqui não utilizo o termo como sinônimo de integrista, mas para designar aqueles que combateram a Teologia da Libertação.
} 
existem varias controvérsias que começam a se manifestar nas operações de memórias recentemente acionadas. Trata-se do ex-cardeal do Rio de Janeiro que, para muitos, foi o responsável pela virada conservadora da Igreja no Brasil. Tento entender os motivos pelos quais este "príncipe da Igreja", extremamente cioso da sua autoridade e com grande prestigio social, busca construir uma nova narrativa sobre si mesmo e sobre sua atuação enquanto arcebispo e cardeal ao longo do período ditatorial.

\section{Eugenio, o príncipe}

D. Eugenio fez uma carreira brilhante galgando todos os postos possíveis dentro da estrutura eclesiástica. Nasceu no Rio Grande do Norte, em 8 de novembro de 1920 e, aos 11 anos entrou para o seminário da Prainha, no Ceará, onde, no período entre 1931 a 1943, realizou toda a sua formação como padre. Em 15 de agosto de 1954, com 33 anos, foi nomeado bispo auxiliar de Natal, no Rio Grande do Norte, pelo Papa Pio XII. Em 1962, foi nomeado administrador apostólico da Arquidiocese de Natal, função que exerceu até 1964, quando assumiu o cargo de administrador apostólico da Arquidiocese de Salvador, na Bahia; em 1968, foi indicado Arcebispo e Primaz do Brasil pelo Papa Paulo VI. No ano seguinte, no dia 28 de abril de 1969, foi nomeado Cardeal e, em 13 de março de 1971, tornou-se Arcebispo do Rio de Janeiro onde ficou até 25 de julho de 2001. Ao longo da sua carreira, assumiu dezenas de comissões no Vaticano, onde atuou com muita proximidade da Cúria Romana, e tem sido considerado um dos bispos mais influentes da América Latina junto ao Papa João Paulo II. Também a ele é atribuída a responsabilidade pela renovação pela qual passou a Igreja no Brasil.

A trajetória de D. Eugenio é muito importante não só pelos cargos que ocupou, mas pela sua grande capacidade organizativa e pelas iniciativas no campo do apostolado social. Sua atuação à frente da Igreja no Rio Grande do Norte foi importante para os rumos que a instituição católica passou a ter ao longo dos anos de 1950 e 1960.

Durante essas décadas, o Nordeste brasileiro foi símbolo de pobreza, miséria e alvo de iniciativas políticas que marcaram as disputas entre comunistas e anticomunistas. Estes, representantes dos setores da oligárquica rural, haviam sido tradicionalmente apoiados pela Igreja, mas foi também o período em que importantes setores do clero e alguns bispos 
passaram a tomar consciência de que tal alinhamento político havia se esgotado e que para derrotar os comunistas era necessário desenvolvimento econômico com inclusão social, fixação do homem na terra através de uma reforma agrária e da sindicalização rural. Foi o período do surgimento da Aliança para o Progresso, que preconizava a necessidade de uma modernização no campo latino-americano para evitar a cubanização do continente. Este objetivo sintonizava com os medos alimentados pela Igreja e, esta coincidência, se traduzia em recursos que chegavam através da Igreja Católica norte-americana. Neste mesmo contexto surgia o projeto de construção da Superintendência de Desenvolvimento do Nordeste (Sudene), acalentado pela CNBB e por amplos setores do nacionaldesenvolvimentismo, que tinha como norte exatamente o desejo de que o Nordeste se desenvolvesse e deixasse de ser objeto da ação dos comunistas.

D. Eugenio se projetou exatamente nesta conjuntura sendo, inclusive, pioneiro no uso do rádio como instrumento político-pedagógico, na luta pela fundação da Sudene e, sobretudo, na organização de sindicatos, na sindicalização rural e pela reforma agrária que, como já apontado, era uma das prioridades da própria Aliança para o Progresso. D.Eugenio teve sua memória perenizada pela fundação do Movimento de Educação de Base (Mebe), que teve como dirigente o conhecido educador católico Paulo Freire. Também se destacou na luta pela fundação da CNBB e da Campanha da Fraternidade. Tais credenciais fizeram com que D. Eugenio se transformasse em uma importante liderança da Igreja no Brasil.

Em 1968, ano do Ato Institucional n.5 e através do qual a ditadura institucionalizava a tortura, D. Eugenio, em seu discurso de posse como Arcebispo e Primaz do Brasil, explicitava a sua posição frente aos desafios que teria pela frente e quais seriam as suas prioridades:

1- Construir uma pastoral de conjunto como meio de

(...) integração de todas as forças vivas com o objetivo de levar a todos os homens a união cada vez maior com o Pai, entre nós, em Cristo, no dom do Espírito pela mediação visível da lgreja. ${ }^{3}$

2- Promoção integral do homem

(...) não enfocado apenas sob o prisma espiritual mas aberto à realidade terrestre, onde ele luta, onde ele conquista o céu. Uma ampla atividade no campo da promoção

\footnotetext{
${ }^{3}$ Ver site de D.Eugenio: domeugeniosales@webnode.com.br.
} 
Passagens. Revista Internacional de História Política e Cultura Jurídica, Rio de Janeiro: vol. 3, $\mathrm{n}^{\circ}$. 2, maio-agosto 2011, p. 203-216.

humana, um esforço constante pela justiça (....) entretanto, que este esforço, que esta preocupação pelo desenvolvimento seja sempre visto sob o ângulo da nossa Redenção em Cristo. E criar condições para que o homem se aproxime de Deus.

3- Abertura à Igreja Universal conforme os ensinamentos do

(...) Vaticano II, no Christus Dominus é peremptório quando impõe ao Brasil o dever de preocupar-se não apenas com sua Diocese mas também com as necessidades da Igreja Universal.

Nenhuma palavra sobre a conjuntura política pela qual passava a sociedade brasileira. As metas anunciavam suas prioridades e sobre as quais D. Eugenio se dedicaria ao longo da sua carreira como Arcebispo e Cardeal. E, sobretudo anunciava sua irrestrita adesão ao Vaticano e à disciplina da Igreja vista como algo em si mesma.

Algo importante a ser ressaltado é que aquela era também uma conjuntura marcada pelas diretrizes oriundas do Concílio Vaticano II e, sobretudo, como tais diretrizes seriam traduzidas para a realidade latino-americana. Era o ano de Medellín e em que se projetava uma teologia que se pretendia renovadora da visão da Igreja sobre a relação dos homens com a história. No entanto, D. Eugenio, falando naquele contexto, apenas ressaltava o sentido de pertencimento à Igreja Universal e enfatizava a ideia de que o desenvolvimento humano sempre deveria ser visto como Redenção em Cristo, como se a dimensão humana só se realizasse nesta perspectiva.

Em 1971, quando da sua posse com Arcebispo do Rio de Janeiro em substituição a D. Jaime de Barros Câmara, um bispo tradicionalista, mas que havia sido profundamente atingido pelo assassinato de seu sobrinho pelas forças repressivas do regime, D. Eugenio afirmava que suas palavras eram de

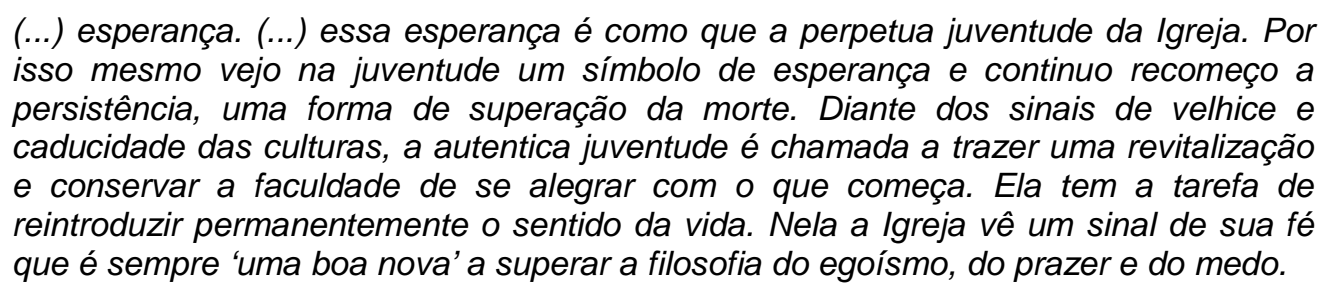

Estaria ele se referindo à juventude representada pelo sobrinho de D. Jaime? Ele convocava a juventude católica para ser portadora dessa "boa nova" de forma a reinventar a alegria. Mas ele dizia ainda que 
Passagens. Revista Internacional de História Política e Cultura Jurídica, Rio de Janeiro: vol. 3, n․ 2, maio-agosto 2011, p. 203-216.

(...) Em uma época de tantas divergências e discórdias, características de um período de transição do mundo, a lgreja, inserida na alma dos homens, participa de todas as suas agruras e apreensões. Tenho bem nítida a minha missão na Guanabara de ser, em Cristo, como sacramento de unidade, de convergência, de todos os homens de boa vontade que querem trabalhar na construção de um mundo mais humano e mais cristão.

A indicação de D. Eugenio como Arcebispo do Rio de Janeiro se deu em meio a uma crise dentro da Igreja no Rio de Janeiro e a sua designação fora produto de um acordo da Nunciatura com os militares, que não admitiam que D. Helder Câmara, até então bispo auxiliar, fosse o sucessor de D. Jaime Câmara. A chegada do novo bispo havia causado mal-estar entre o clero, que nutria expectativa em relação a $D$. Helder e que já entendia que a Igreja tinha que se posicionar frente às crescentes violações dos direitos humanos, e, sobretudo, contra o modelo econômico adotado pelo regime que já naquele período era objeto de denúncia da própria CNBB.

Como que desconhecendo aquela realidade, D. Eugenio afirmava que "(... ) Não estou ligado a nenhuma ideologia, a nenhum sistema econômico. Devo ser instrumento de unidade, colocando-me sempre a serviço do Evangelho."

E acrescentava que

(...) às autoridades, responsáveis pelo bem efetivo exercício do bem comum devemos respeito e obediência :"Quem resiste à autoridade resiste a Deus (RO. 13,1,2,55)". E aqui poderemos lembrar as palavras recentes pronunciadas pelo Santo Padre:"Temos a profunda convicção de que uma leal harmonia entre a Igreja e o Estado baseada no sólido fundamento do respeito sincero pela independência recíproca e pelo direito de ambas as partes, não só é proveitosa para a lgreja, mas também é em igual medida para a sociedade civil. E, isto, não porque a paz religiosa é, de per si, um contributo precioso que dá à serenidade da vida nacional mas também porque a religião está em condições de cooperar com os valores espirituais e morais, na formação humanitária dos cidadãos e, em particular, da juventude. As vitórias da nossa pátria são as nossas vitórias; suas falhas e defeitos são nossos sofrimentos .

E foi em nome dessa colaboração que o arcebispo se manteve calado sobre as suas relações com o regime e em todas as ocasiões em que foi instado a se pronunciar não o fez. Seu apostolado no Rio de Janeiro foi marcado pelo sentimento de extrema obediência às autoridades e impôs essa concepção ao clero que, ao longo de todo o tempo, teve que se calar sobre inúmeras questões políticas importantes e não pôde, inclusive, desenvolver as Comunidades Eclesias de Base (Cebes).

Todavia, em 2001, ao se afastar o arcebispado, começou a surgir outra narrativa sobre a sua trajetória, diferente daquela já consolidada e na qual se evidenciava sua aliança 
com o regime e indiferença na defesa dos direitos humanos. E até mesmo sobre a sua timidez diante da política econômica do regime, que causava tantos sofrimentos aos setores mais pobres da população, e que era objeto de inúmeros pronunciamentos da CNBB. Suas declarações, e particularmente os artigos publicados semanalmente por importantes jornais com circulação nacional, versaram e ainda versam sobre questões doutrinarias relativa à moral católica.

Curiosa com essa operação memorialística que se iniciava, entrevistei um bispo, expoente da Teologia da Libertação e pioneiro na luta contra a ditadura, sobre quais eram as suas memórias sobre a atuação de D. Eugenio frente a dois episódios que me parecem emblemáticos e que, de alguma maneira, eram recuperados na narrativa que começava a surgir. O primeiro diretamente relacionado com a repressão a membros do próprio episcopado e outro relativo à defesa dos perseguidos políticos.

E que episódios eram estes?

Primeiramente, a perseguição no interior do episcopado. No dia 20 de setembro de 1976, um comando do Exercito havia sequestrado D. Adriano Hipólito, bispo de Nova Iguaçu, município do Rio de Janeiro. O sequestro, comandado por militares descontes com as diretrizes do regime que começavam a construir a chamada "transição lenta e gradual" proposta pelo general Ernesto Geisel, ocorreu durante a madrugada e, horas depois, o bispo foi deixado nu em uma rua abandonada da cidade. Tratava-se de humilhar e, ao mesmo tempo, dar um recado aos outros membros do episcopado que se pronunciavam explicitamente em oposição ao regime. E, no caso específico do bispo de Nova Iguaçu, tratava-se de impedir o crescimento dos movimentos comunitários que ali se desenvolviam sob a liderança da Igreja, mas com a participação de vários grupos da esquerda laica.

Segundo meu entrevistado, apesar do sequestro de D. Adriano ter ocorrido dentro da diocese do Rio de Janeiro, D. Eugenio se manteve alheio ao episódio. Mas, no entanto, havia Ihe telefonado para avisar-Ihe que ele seria o próximo a ser sequestrado e the pedia que recebesse um determinado militar, que se propunha a dialogar. No dia e hora marcada, 0 bispo em questão recebeu o tal militar e qual não foi a sua surpresa quando descobriu que, na realidade, o que estava sendo articulado era a sua colaboração com os órgãos de repressão. Queriam que ele Ihes indicasse aqueles militantes que, segundo diziam, estavam 
infiltrados na Igreja ${ }^{4}$. Além deste episodio, meu entrevistado me relatou outros fatos que podem corroborar com a visão de que D. Eugenio era realmente próximo dos militares e que com eles colaborava. Aliás, algo que ele mesmo relata em entrevistas publicadas na revista Veja e onde manifesta a sua amizade com o general Silvio Frota, comandante do Exército no Rio de Janeiro e um dos personagens mais conhecidos do regime.

\section{Ajuda humanitária a ex-preso políticos}

Algo próximo ocorreu com Ana Miranda, ex-presa política que, em 1974, foi à procura de D. Eugenio. Ana havia feito um concurso publico, mas se encontrava impedida de assumilo porque para que sua posse fosse efetivada era necessário que os órgãos policiais atestassem que nada havia contra ela. No Brasil, até a constituição de 1988, era necessário obter um documento, tristemente conhecido como atestado ideológico, sem o qual nenhum brasileiro que houvesse sido preso ou investigado poderia trabalhar no serviço público, tirar passaporte, entre várias impossibilidades. Ana, a conselho de um amigo da família que se dizia próximo ao arcebispo, conseguiu marcar uma audiência com D. Eugenio para pedir-lhe que intercedesse junto ao general Silvio Frota, no sentido de que o tal atestado ideológico lhe fosse liberado. Segundo relato de Ana, a entrevista foi um verdadeiro interrogatório ao final do qual o Arcebispo pegou o telefone e, na frente dela, ligou para comandante e lhe disse que ela não era recuperável e que as sanções deveriam permanecer. ${ }^{5}$

Curioso é que essa relação privilegiada com as autoridades já havia se explicitado no seu discurso na abertura do oitavo Congresso Eucarístico Nacional, realizado em Brasília, em maio de 1970. Naquela ocasião dizia o arcebispo:

\footnotetext{
(...) Meus irmãos, se cremos que esse momento da vida de nosso país está intimamente vinculada à História da Salvação, peçamos ao Cristo Eucarístico "clareza para ver, lucidez para diagnosticar e solidariedade par atuar" para que possamos "penetrar todo o processo de mudança que se registra em nosso país e em todo o mundo, com os valores evangélicos" e, desta forma, os sagrados direitos de toda pessoa humana sejam respeitados e assim todos possam acreditar em Boa Nova de que Deus é a vocação do homem. Governantes e governados partilharão os caminhos do Senhor, na justiça, na paz e no amor. Peçamos ao Cristo Eucarístico a graça do dialogo entre as gerações. Que nossa juventude seja, no Brasil, a centelha que estimule a vida para que,a través dela, ä Igreja seja a verdadeira juventude do mundo.
}

\footnotetext{
${ }^{4}$ Entrevista realizada em de agosto de 2010.

${ }^{5}$ Relato de Ana Miranda, feito em março de 2010.
} 


\section{Ajuda aos refugiados do Cone Sul}

A despeito de todos estes relatos, durante o ano de 2001, quando D. Eugenio se retirou da direção da Igreja do Rio de Janeiro, começaram a surgir várias reportagens, particularmente nos jornais O Globo e O Estado de São Paulo, sobre uma suposta militância que ele teria tido na defesa dos direitos humanos durante a ditadura e, em especial, a sua militância em defesa de refugiados argentinos e uruguaios. Segundo palavras de D. Eugenio, essa atuação também teria sido realizada em defesa de brasileiros perseguidos durante a ditadura. Nestas reportagens, D. Paulo Evaristo Arns, arcebispo de São Paulo e conhecido pela sua incansável defesa dos direitos humanos e pela sua presença nas prisões brasileiras, instado a falar desta atuação de D. Eugenio, respondeu que, para ele, esta era uma grande novidade.

Para meu entrevistado, mesmo que esta atuação tenha sido verdadeira isso não quer dizer que ele o fizesse em nome da lgreja. E lembrou que os recursos econômicos para os refugiados, que eram oriundos das Nações Unidas e da Caritas, apenas eram administradas pela Cúria do Rio de Janeiro e que a atuação do Cardeal era negociada com as autoridades brasileiras. Para este bispo, a atuação de D. Eugenio em defesa de um ou outro perseguido político sempre teve caráter pessoal e não de Igreja já que ele utilizava a sua influência pessoal para prestar favores a amigos ou àqueles a quem ele devia alguma consideração.

Essas observações são explicitadas pelo próprio D. Eugenio que, ao relatar sua atuação, ressalta a sua amizade com as famílias dos perseguidos ou que respondia ao pedido de alguém a quem ele considerava católico. Nestas entrevistas, o Arcebispo fala da sua amizade com o general Silvio Frota, comandante do Primeiro Exército. Afirma ainda que não dava nenhum passo no campo da política sem comunicar às autoridades militares.

\section{Solidariedade com os presos políticos}

Em relação aos presos políticos a atuação do Cardeal sempre foi de distanciamento. Proibia os padres de visitarem os presos políticos e, a partir de 1977, por ocasião da Páscoa, circulava pelos pavilhões, onde estes presos se encontravam, com um cortejo de repórteres. 
Nestas ocasiões, a coisa mais estranha era o seu gesto de estender o anel de cardeal para que algum preso o beijasse.

Também negava pedidos de padres que solicitavam sua permissão para visitar os presos políticos e, sobre tal proibição, há um caso especial, mas que ilustra como o Cardeal agia. Em 1976, o padre italiano Renzo Rossi, que vivia na Bahia, onde dava permanente apoio aos presos políticos daquele estado, solicitou ao Cardeal autorização para visitar os presos políticos do Rio de Janeiro. A reposta não tardou e, através de uma carta, D.Eugenio o proibiu de ir aos presídios do Rio de Janeiro alegando que para isso existia o capelão penitenciário e que não era recomendável a defesa daqueles presos. ${ }^{6}$

\section{Solidariedade para com as famílias dos presos}

Existem inúmeros depoimentos de familiares dos presos políticos que afirmam que, por serem católicos, haviam procurado o Cardeal para localizar seus entes ou até mesmo para pedir que lhes ajudasse de alguma maneira. Segundo a maioria destes depoimentos, o Cardeal foi indiferente aos seus sofrimentos e muitas vezes não os recebia. Durante a campanha pela anistia, houve inúmeras tentativas de aproximação com o Cardeal, que sempre se recusava a receber os familiares ou aqueles que buscavam uma palavra de apoio àquele movimento. $E$ interessante ressaltar que foi exatamente neste período que a CNBB se pronunciava pela Anistia Ampla, Geral e Irrestrita, campanha que empolgava setores importantes da sociedade brasileira.

Diante de tantas evidencias, perguntei-me por que o cardeal havia iniciado essa operação memorialística já que ele, como o grande príncipe da lgreja brasileira, não teria nenhuma necessidade em ser reconhecido como opositor do regime militar, na medida em que esta questão é por demais fluida na sociedade brasileira de hoje. Minha hipótese é de que o discurso do cardeal foi dirigido para dentro da própria Igreja, na busca de uma incorporação a uma memória institucional sobre o período, e, para tanto, ele aciona seus operadores de memória, que foram os jornais de grande circulação nacional, para produzir uma nova narrativa, intitulada de "justiça a um cardeal". Além do lançamento de um livro de memórias autorizadas que teve grande repercussão na mídia e de se colocar à disposição de

\footnotetext{
${ }^{6}$ Carta escrita em 1976. Acervo pessoal do padre Renzo Rossi.
} 
intelectuais católicos que o procuram em busca de informações históricas. Com estes pesquisadores, o cardeal é pródigo e assim ele vai produzindo novas versões sobre a sua trajetória pastoral. O texto mais notável é o de Kenneth P. Serbin, cujo livro ${ }^{7}$, que obteve imenso sucesso, apresenta D. Eugenio como sendo o artífice da luta diplomática para melhorar a imagem do Brasil no exterior e que, com sua amizade com o general Muricy ${ }^{8}$, terminou por construir um diálogo entre os militares e a lgreja onde determinados temas relativos à defesa dos direitos humanos eram debatidos. É interessante como o autor afirma que

D. Eugenio não apoiava o regime. Apesar de anticomunista, não se alinhava com o setor tradicionalista e direitista do catolicismo, que aplaudira o golpe. Ele tinha compromissos com a reforma da sociedade. Ajudou a construir os alicerces para o catolicismo progressista no Brasil, embora evitasse os elementos radicais e confiasse menos nos movimentos populares e mais nas classes altas e médias para a obtenção da mudança social. ${ }^{9}$

O importante a ressaltar é que esta iniciativa do Cardeal tem sido coroada de êxito até mesmo entre aqueles que conhecem episódios que contradizem as versões que vêm sendo divulgadas. De alguma forma, esta operação memorialista termina por se somar às inúmeras memórias retroativas, segundo as quais o golpe militar parece ter sido apenas um ato de loucura de alguns generais, já que poucos são aqueles que, na atualidade, se reconhecem como base de apoio ou até mesmo operacional da ditadura.

No entanto, devemos atentar para o fato de que a memória sobre o significado do golpe militar ainda está em disputa. Os militares continuam se negando a abrir seus arquivos, o governo tem tido ao longo dos anos atitudes dúbias, controvertidas, sobre o tema e o mundo político permanece comprometido com todas as operações de esquecimento. Todavia, sempre que está em pauta o significado histórico do golpe, forças ocultas - mas não desconhecidas - se apresentam para falar em esquecimento e pacificação.

Penso que os operadores de memória, aqueles que, ignorando o sentido político dos relatos sobre a trajetória de personagens como D. Eugenio, terminam por se somar às operações de esquecimento. E os pesquisadores não estão ausentes nesta operação. De

\footnotetext{
${ }^{7}$ Serbin, Keneth (2001). Diálogos na sombra: Bispos e Militares, tortura e justiça social na ditadura. Tradução de Carlos Eduardo Lins e Silva. SP: Companhia das Letras.

${ }^{8}$ Foi dos notáveis do regime militar sendo, inclusive, cogitado para suceder o general Costa e Silva. Também foi o autor de um conhecido relatório no qual ele faz uma analise psicológica dos presos políticos que serviria para que fossem definidos critérios disciplinares que seriam utilizados no cotidiano das prisões.

${ }^{9}$ Serbin, K. (2001). Op. cit., p. 159.
} 
um lado, aqueles que buscam dar voz àqueles setores do catolicismo que se mantiveram na oposição ao regime ou até mesmo daqueles bispos que ajudaram a construir o consenso necessário ao golpe militar, como é o caso de D. Evaristo Arns, mas que ao longo do processo se conscientizaram da brutalidade do regime. E de outro, aqueles que buscam em personagens como D, Eugenio, construir uma contra-memória capaz de incorporá-lo à narrativa oficial segundo a qual foi esta instituição a principal responsável pela derrubada do regime militar. Creio que a busca por estas múltiplas memórias construídas no campo da institucionalidade católica pode ser um programa importante para os jovens historiadores que se identificam com o tema já que, como afirma Elizabete Jelin, a memória não é o passado, mas uma maneira em que os sujeitos buscam dar sentido ao vivido em relação ao presente e em função de um futuro desejado. E, nesta dimensão, o presente contém e constrói as experiências passadas e as futuras.

\section{Referência Bibliográfica}

Serbin, Keneth (2001). Diálogos na sombra: Bispos e Militares, tortura e justiça social na ditadura. Tradução de Carlos Eduardo Lins e Silva. SP: Companhia das Letras. 